\title{
1 Quantitative three-dimensional nondestructive imaging of whole anaerobic ammonium-oxidizing bacteria
}

\section{Abstract}

the treatment of nitrogenous wastewater. These functions are closely related to the unique biophysical structure of anammox bacteria. However, the research on the biophysical ultrastructure of intact anammox bacteria is lacking. In this study, in-situ three-dimensional nondestructive ultrastructure

10 imaging of whole anammox cell was performed using synchrotron soft X-ray nano-computed

11 tomography and the total variation-based simultaneous algebraic reconstruction technique (TV-SART).

12 Statistical and quantitative analyses of the ultrastructures of intact anammox bacteria were performed.

13 The linear absorption coefficient values of the ultrastructures of anammox bacteria were calculated and

14 the asymmetric structure of the anammox bacteria was quantified. On this basis, the shape adaptation of

15 the anammox bacteria responses to $\mathrm{Fe}^{2+}$ were explored, and the underlying regulation mechanism of $\mathrm{Fe}^{2+}$

16 on anammox bacteria was explored. Furthermore, a promising method to study the biophysical properties

17 of cells in different environments and engineering processes was proposed. 


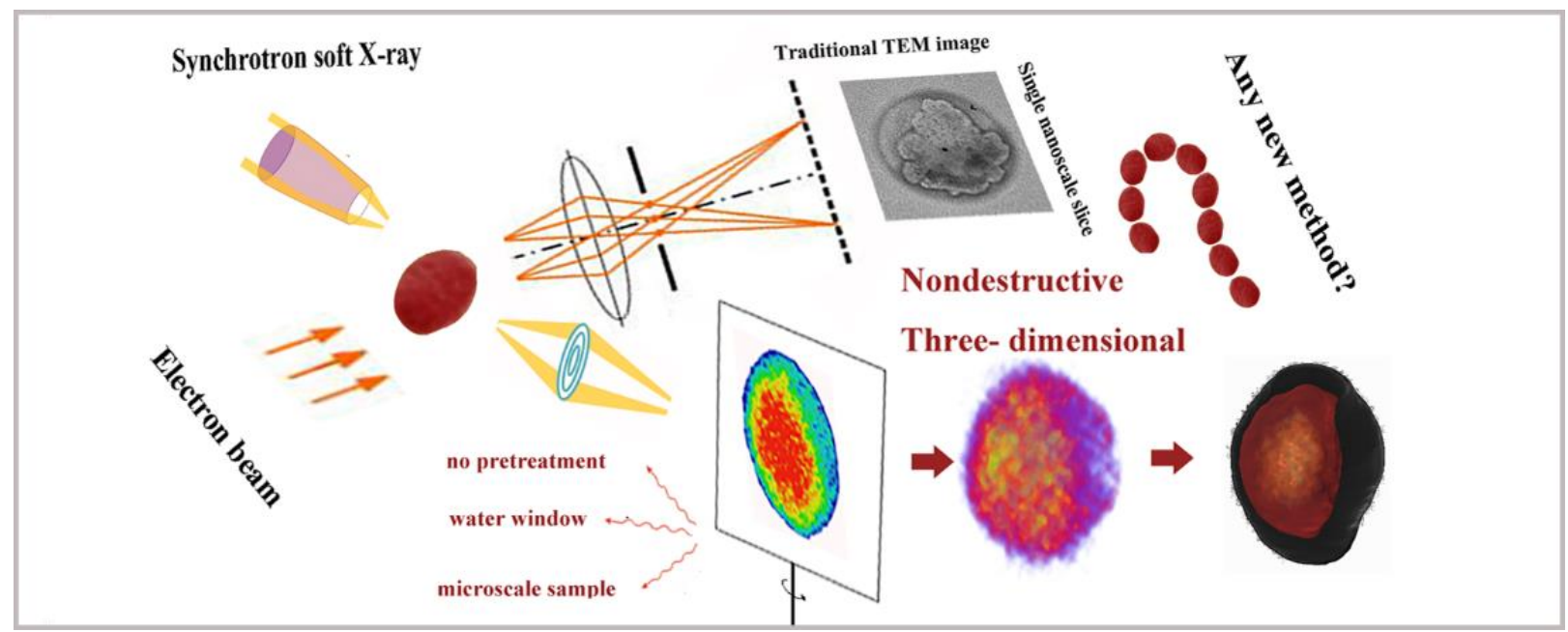

Keywords: Synchrotron; Three-dimensional nondestructive - imaging; Anammox;

\section{Statement of Significance}

24 physiological function depends on the unique morphology of anammox bacteria. In this study, 


\section{Introduction:}

Anaerobic ammonium oxidizing (anammox) bacteria are widespread bacteria in rivers (1), marine

33 sediment (2), paddy soil (3), oil fields (4), and wastewater treatment plant (5). Anammox bacteria are

34 estimated to account for up to $50 \%$ of the nitrogen removal from the oceans (6). Moreover, the anaerobic,

35 autotrophic anammox bacteria obtain energy from the oxidation of ammonium with nitrite to nitrogen

gas $(2,7,8)$. This property makes anammox bacteria suitable for the removal of nitrogen compounds

from nitrogenous wastewater due to their environmental friendliness and cost-effectiveness (9). Further,

anammox bacteria are prokaryotic organisms but contain a fairly large organelle structure. Anammox

bacteria have an irregular, membrane-bounded intracellular compartment called the anammoxosome (10).

The anammoxosome organelle is unique and only exists in anammox bacteria (11). The key catabolic metabolism occurs in anammoxosome $(11,12)$. In addition, anammox membranes contain unique membrane lipids called ladderanes (13). Ladderane lipids are calculated to have a density of $1.5 \mathrm{~kg} / \mathrm{dm}^{3}$ and are unique to anammox bacteria (14). The dense membrane reduces the leakage of protons and valuable intermediates of the anammox process (15). This complex biological structure makes anammox bacteria unique in terms of biological morphology. in aqueous or soil environments (16). Caulobacter crescentus adapts to different environmental challenges by adjusting their shape (17). The stalk of Caulobacter was elongated up to $30 \mu \mathrm{m}$ when faced with phosphate starvation (18) and this stalk elongation structure was hypothesized to enhance phosphate

51 absorption (19). Moreover, Shewanella alga $\mathrm{Br} Y$ adapts to starvation by reducing the cell volume from 
520.48 to $0.2 \mu \mathrm{m}^{3}$; the starved cell can be resuscitated to the prior volume in a suitable environment (20).

53 Similar morphological changes were reported in Mn-oxidizing bacteria, i.e., Halomonas meridiana and

54 Marinobacter algicola in response to Mn (II)-induced stress. The cell length of Halomonas meridiana and Marinobacter algicola increased significantly to improve the Mn (II) oxidizing ability (21). The cell morphology of bacteria can be adapted dynamically depending on environmental conditions, a requirement for optimal survival and growth (17). Thus, morphology research is of great significance.

However, the morphology of intact anammox bacteria has not been investigated to date and the shape adaptations of anammox bacteria under different environment conditions remain unclear. electron microscope (TEM) technique. In spite of the successful application of the TEM method for the analysis of the anammox structure, the limited transmission depth, the inherently low contrast, and the destructive pre-treatment including dehydration, embedding, and the ultrathin section (22) made it impossible to date to image the 3D structure of intact anammox bacteria. The development of cryoelectron tomography has resulted in many breakthroughs in the imaging field (23) but the method requires that the sample has to be cut into nanoscale slices (at most up to 500nm). Limited by the weak penetration, cryo-electron tomography is incapable of high throughput imaging for micron-thick cells (24). To date, the structure of the whole anammox bacteria cell has not been determined. The lack of effective in-situ imaging methods of whole anammox bacteria limits the exploration of the unique metabolic mechanism of anammox bacteria. Thus, an in-situ nondestructive method for the morphological study of intact

71 anammox bacteria is urgently required to reveal the microstructure and related metabolic functions of anammox bacteria. 
73 Synchrotron soft X-ray nano-computed tomography (CT) is an in-situ nondestructive imaging

74 technology. It provides a method to obtain a non-destructive 3D image of whole hydrous cells.

75 Synchrotron soft X-ray photons can penetrate hydrated specimens up to $15 \mu \mathrm{m}$. This property permits

76 the imaging of the entire intact anammox cell in its natural state without any staining, sectioning,

77 dehydration, or embedding pretreatments $(25,26)$. The synchrotron soft X-ray wavelength is adjustable

78 and by using the "water window" range from $2.3 \mathrm{~nm}$ to $4.4 \mathrm{~nm}$, the absorption of organics is almost an

79 order of magnitude higher than that of the water, thus the organics can be distinguished from the water

80 by natural contrast at $30-\mathrm{nm}$ resolution (26). In addition, this imaging method allows for obtaining the

81 transmission image along the projection direction, as well as providing information on the interior structure of the specimen $(26,27)$. Thus, unlike other imaging methods, synchrotron soft X-ray nano-CT provides a unique opportunity for imaging intact anammox cells in the in-situ state. The synchrotron soft

84 X-ray imaging technique was successfully applied to the 3D mapping of eukaryotic cells, such as the 3D

85 reconstruction of saccharomyces organelles (26), imaging of the structure of hepatitis $\mathrm{C}$ virus (HCV)

86 replicon-harboring cells (28), and research of superparamagnetic iron oxide nanoparticle reactions with

87 a breast cancer cell (29). However, to date, the synchrotron soft X-ray nano-CT technique has not been

88 applied to anammox cells; therefore, this topic requires investigation.

In this study, the synchrotron soft X-ray nano-CT imaging technique was used to image an intact anammox bacteria cell. A reconstruction based on the traditional filtered-back projection (FBP)

91 calculation method was used to reconstruct the numerous image slices. The total variation-based simultaneous algebraic reconstruction technique (TV-SART) was employed in this study to optimize the imaging process and obtain the image information. The linear absorption coefficient (LAC) was 
94 determined based on the TV-SART algorithm. The 3D ultrastructure of the anammoxosome volume ratio,

95 the eccentricity, and the nanoparticles of an intact anammox cell in its natural hydrous state were explored

96 and the shape adaptations of anammox bacteria in response to environmental changes were investigated.

Materials and Methods

\section{Cultivation and purification of the anammox granules}

\section{DNA extraction and PCR amplification from for the granular sludge}

110 Microbial DNA was extracted from the ammonia oxide granular sludge in the EGSB reactor using

111 the E.Z.N.A. ® soil DNA Kit (Omega Bio-Tek). The final DNA concentrations were determined using

112 an ultraviolet-visible (UV-VIS) spectrophotometer (PerkinElmer Lambda 950) and the DNA molecular 
113 mass was determined by gel electrophoresis with $1 \%$ agarose. The V3-V4 regions of the anammox $16 \mathrm{~S}$

114 rRNA gene were amplified with the primer 338F (5'-ACTCCTACGGGAGGCAGCAG-3') and the

115 primer 806R (5'-GGACTACHVGGGTWTCTAAT-3') using polymerase chain reaction (PCR) (ABI

116 GeneAmp 9700). The PCR program was as follows: 3 min of denaturation at $95^{\circ} \mathrm{C}, 27$ cycles of $30 \mathrm{~s}$ at

$11795^{\circ} \mathrm{C}, 30 \mathrm{~s}$ for annealing at $55^{\circ} \mathrm{C}, 45 \mathrm{~s}$ for elongation at $72{ }^{\circ} \mathrm{C}$, and a final extension at $72{ }^{\circ} \mathrm{C}$ for $10 \mathrm{~min}$.

118 A mixture of $4 \mu \mathrm{l}$ of $5 \times$ FastPfu Buffer, $2 \mu \mathrm{l}$ of $2.5 \mathrm{mM}$ dNTPs, $0.8 \mu \mathrm{l}$ of $5 \mu \mathrm{M} 338 \mathrm{~F}$ primer and $0.8 \mu \mathrm{l}$

119 of $5 \mu \mathrm{M} 806 \mathrm{R}$ primer, $0.4 \mu \mathrm{l}$ of FastPfu Polymerase, $0.2 \mu \mathrm{l}$ BSA, and $10 \mathrm{ng}$ template DNA was added to

120 the reaction system; deionized water was added to obtain $20 \mu \mathrm{l}$. Two parallel PCR reactions were

121 performed at the same time. The resulting PCR products were extracted from $2 \%$ agarose gel and further purified using the AxyPrep DNA Gel Extraction Kit (Axygen Biosciences) and were quantified by QuantiFluor ${ }^{\mathrm{TM}}$-ST (Promega).

\section{Characteristic analysis of the anammox bacteria}

\section{Diversity analysis of the anaerobic granular sludge}

The Illumina MiSeq PE300 platform (Illumina, San Diego, USA) was used for sequencing of the purified amplicons and the raw reads were deposited into the National Center for Biotechnology Information (NCBI) Sequence Read Archive (SRA) database. The operational taxonomic units (OTUs)

130 were clustered with a 97\% similarity cutoff using UPARSE (version 7.1 http://drive5.com/uparse/) and

131 the chimeric sequences were identified and removed using UCHIME. The taxonomy of the 16S rRNA

132 gene sequences was analyzed using the ribosomal database project (RDP) classifier algorithm 133 (http://rdp.cme.msu.edu/) against the Silva (SSU123) 16S rRNA database using a confidence threshold 134 of $70 \%$. 

dehydrated in $50 \%, 80 \%$, and $100 \%$ ethanol for $10 \mathrm{~min} ; 1 \mu \mathrm{L}$ of probe $\mathrm{Amx} 368$ and $9 \mu \mathrm{L}$ of hybridization buffer were added to the enriched anammox bacteria in the hybridization wells $(32,33)$. The probe Amx368 CCTTTCGGGCATTGCGAA labeled with Cy3 at the 5' end was applied to determine the total anammox bacteria. The hybridization was performed in a hybaid oven at $46{ }^{\circ} \mathrm{C}$ for $90 \mathrm{~min}$. The total

141 biomass of the enriched bacteria was stained with $10 \mu \mathrm{L}$ DAPI at $5 \mu \mathrm{g} / \mathrm{ml}$ for 15 min.(34) All operations

142 related to the fluorochromes were conducted in a dark environment to avoid fluorescence quenching.

143 The fluorescence images of the anammox bacteria and total biomass were obtained with a confocal laser

144 scanning microscope (CLSM) (Olympus, FV1200); the excitation wavelength of Cy3 was set at $552 \mathrm{~nm}$

145 and the DAPI dye was set at $488 \mathrm{~nm}$ for the CLSM analysis. The ratio of the anammox to the total

146 biomass was determined using Photoshop software.

148 Image analysis of the anammox bacteria

\section{Synchrotron soft $X$-ray $3 D$ imaging of the anammox bacteria}

150 The synchrotron soft X-ray imaging experiment was performed at the BL07W beamline at the National

151 Synchrotron Radiation Laboratory (NSRL) in Hefei, China.(35) The purified anammox bacteria were 
155 to vitrify the anammox cell so that ice crystal contamination and structural damage of the anammox cells

156 were avoided. Subsequently, the cells were rapidly placed into liquid nitrogen to remain vitrified to

157 prevent radiation damage (36). The copper grids with the purified anammox cells were transferred into

158 the vacuum cryogenic chamber of the soft X-ray instrument for imaging; 0.52 Kev photon energy was used to take advantage of the high natural contrast of the organics in the "water window" (37). A visible

$167(\mathrm{CCD})$.

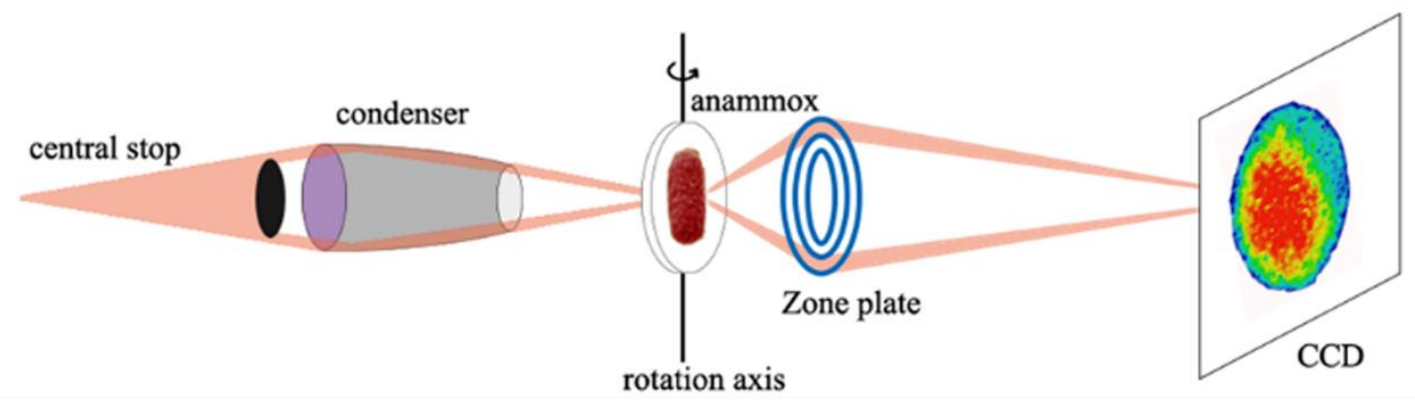

Fig 1. Schematic of the synchrotron soft X-ray nano-CT imaging process of the anammox cell. 
171 To obtain the 3D information of the anammox ultrastructure, a tomographic reconstruction of the 131

172 images obtained from different angles was conducted using the FBP algorithm. Some angles were

173 missing because of grid shading and the algebraic reconstruction technique (ART) was used for the

174 missing wedges. The TV-SART in the TomoJ software was applied to obtain detailed structural

175 information (38). The reconstruction results of the TV-SART algorithm were evaluated using the LAC

176 values. The LAC represents the inherent ability of a substance for absorption the soft x-ray (39), and the

177 images depicting the LAC were segmented to identify the different organelle structures and chemical

178 composition $(40,41)$. Amira software was used to segment the reconstructed anammox bacteria cell,

179 calculate the LAC values, measure the number of pixels of the anammoxosome organelle and anammox

180 bacteria cell, and to create movies $(26,42)$.

\section{Anammox imaging with TEM}

182 The anammox bacteria were then fixed in $4 \%$ formaldehyde in a phosphate buffer solution on ice

183 overnight. Subsequently, they were dehydrated in graded ethanol $(50 \%, 70 \%, 80 \%, 90 \%, 95 \%$ and $100 \%$

184 ethanol). Next, the anammox bacteria were embedded in Epon resin and cut into 70nm thick slices using

185 an ultramicrotome (Leica EM UC7)(10) and the sections were transferred to 100-mesh copper grids for

186 the TEM analysis. The TEM imaging was performed with a HITACHI HT7700 instrument at an

187 accelerating voltage of $100 \mathrm{kV}$. 
191 Iron plays a key role in anammox bacteria growth and affects the anammox activity and nitrogen removal

\section{Results}

\section{Characteristics of anammox bacteria}

203 The anammox granules sampled from the EGSB reactor are shown in Fig 2(a). The round granules

204 were deep red and the diameter range was $1.2 \mathrm{~mm}$ to $6.0 \mathrm{~mm}$. The microbial diversity analysis of the

205 anammox granular sludge at the genus level is shown in Fig 2(b). The anammox bacteria included three

206 genera: Candidatus Jettenia, Candidatus Brocadia, and Candidatus Kuenenia, accounting for 26.36\%,

$2074.22 \%$ and $1.40 \%$ of the total microbial biomass in the EGSB reactor, respectively. The purified

208 anammox cells had about 95\% purity based on the Percoll density gradient centrifugation (Fig 2(c)).

209 Although three genera of anammox bacteria were observed in the reactor, these three genera of 
bioRxiv preprint doi: https://doi.org/10.1101/709188; this version posted July 22, 2019. The copyright holder for this preprint (which was not certified by peer review) is the author/funder. All rights reserved. No reuse allowed without permission.

Candidatus Jettenia, Candidatus Brocadia, and Candidatus Kuenenia had similar structural

211 characteristics, including three separate compartments: periplasm, cytoplasm, and anammoxosome.

212 Furthermore, the anammoxosome volume ratio in these three genera accounted for more than $60 \%$ of the

213 anammox bacteria volume (11).
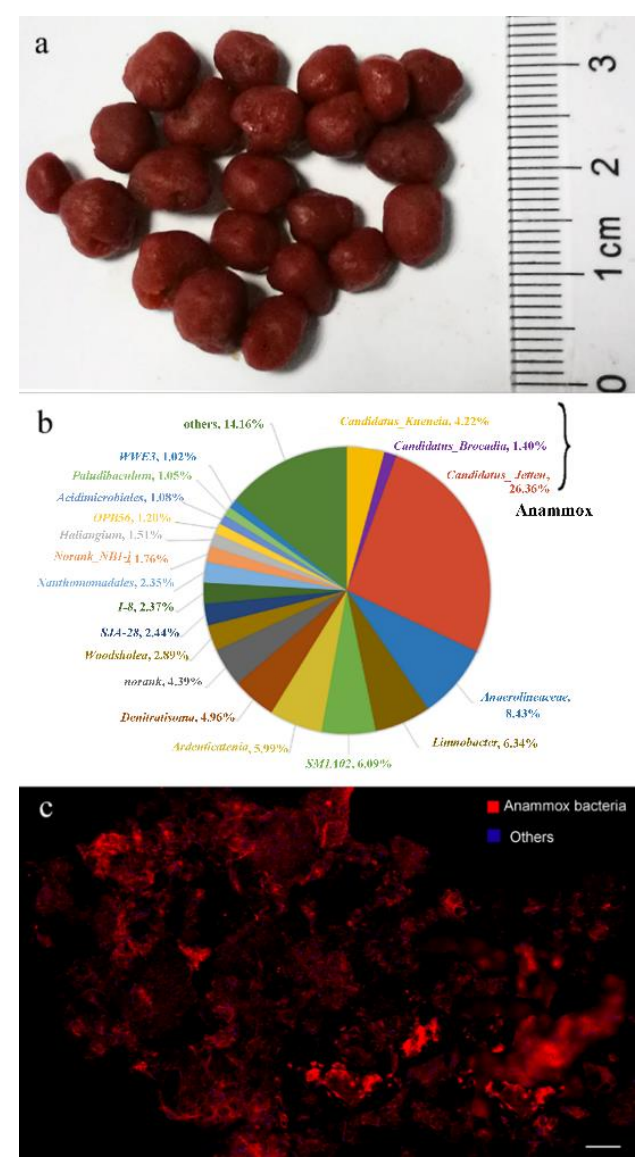

215 Fig 2. The anaerobic granular sludge in the EGSB reactor. (a) Anaerobic granular sludge sampled from

216 the EGSB reactor. Scale bar shows $20 \mathrm{~mm}$. (b) Microbial diversity analysis of the anaerobic granular

217 sludge. (c) Confocal laser scanning microscope image of the anaerobic granular sludge. (Scale bar shows $218200 \mu \mathrm{m}$. 


\section{Synchrotron soft X-ray transmission imaging and reconstruction of anammox bacteria.}

221 Fig S1 shows the synchrotron soft X-ray projection image of the intact cells; 131 projection images of

222 the anammox bacteria at different angles were collected, and the 3D structure of the anammox bacteria

223 was reconstructed using the FBP algorithm in the original soft X-ray microscopy system as shown in the

224 Supplementary Movie 1. Fig S2 (a) shows a screenshot of the anammox bacteria. The structure inside

225 the anammox bacteria was inferred to be anammoxosome. The slice images of the anammox bacteria are

226 shown in Fig S2 (b) and the tomogram of the anammox bacteria is shown in Supplementary Movie 2.

227 The soft X-ray absorption of all areas inside the anammox bacteria can be visualized and the grayscale

228 difference is shown in the slice image.

229 To further investigate the interior ultrastructure of the anammox bacteria, the TV-SART (38) algorithm

230 was used to reconstruct the anammox bacteria. The anammox bacteria in Fig S2 have a strong and

231 heterogeneous high-absorption structure but the absorption difference inside the high-absorption

232 membrane could not be distinguished due to limitations of the FBP algorithm. In addition, some artifacts

233 were observed in the greyscale 3D reconstruction video (Supplementary Movie 1) and were attributed to 
234 missing angles. The TV-SART algorithm can compensate for these drawbacks and provides the LAC

235 values.

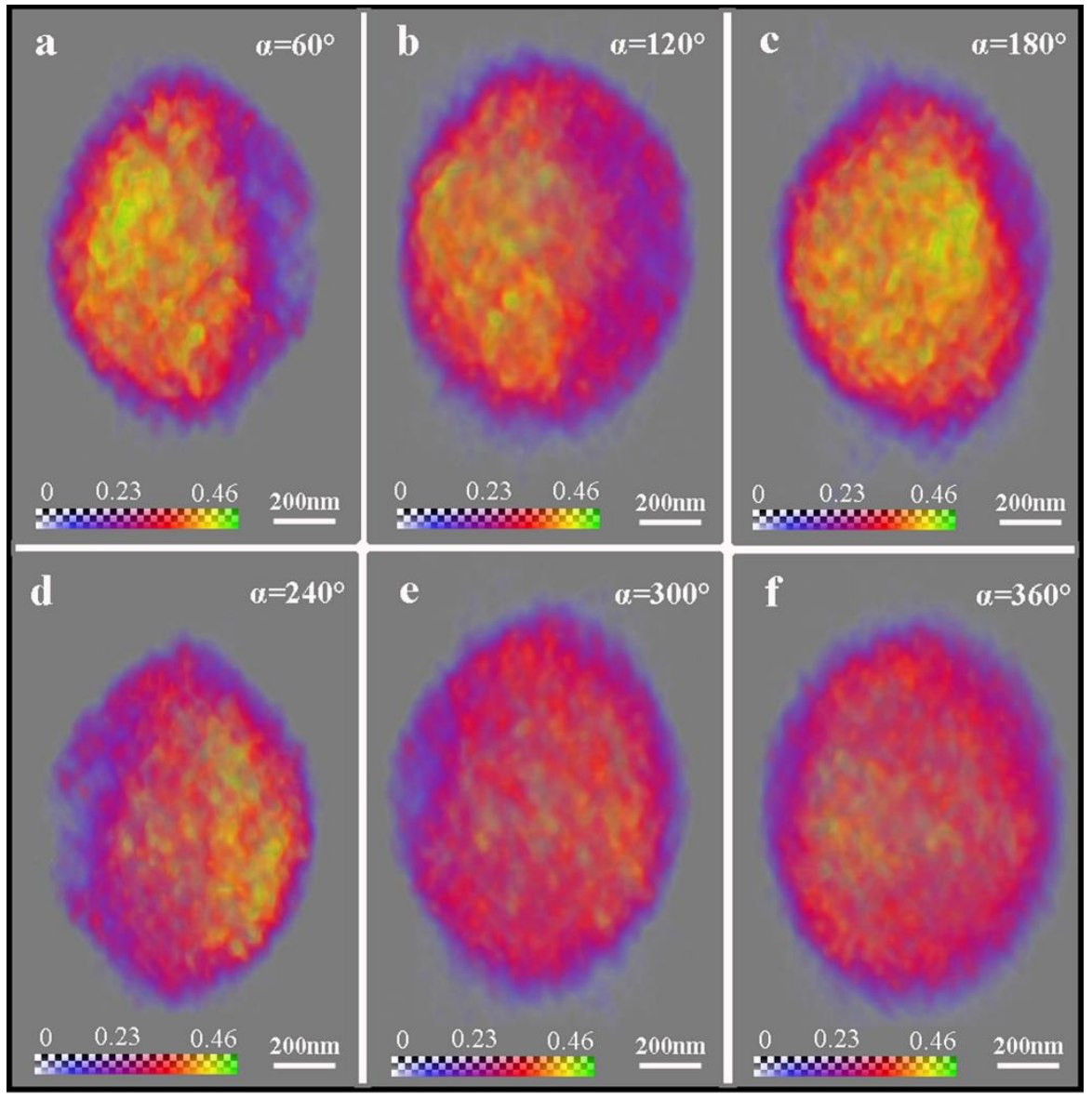

236 Fig 3. The intact anammox cell reconstructed using the TV-SART algorithm. (a), (b), (c), (d), (e), and (f)

237 correspond to $60^{\circ}, 120^{\circ}, 180^{\circ}, 240^{\circ}, 300^{\circ}$, and $360^{\circ}$, respectively.

240 Supplementary Movie 3. Fig 3 shows the reconstructed anammox bacteria cell at different rotation angles

241 with $60^{\circ}$ intervals. The colormap ranges from 0 to 0.46 and represents the LAC value corresponding to

242 the differences in the structure or composition. The LAC reconstruction provided a clearer representation

243 of the ultrastructure of the anammox bacteria. The cluster (in yellow) inside the anammoxosome 
244 membrane had a higher LAC value and some nanoparticles (in green) had extremely high LAC values

245 (Fig 3). Fig 4 shows the slice image of the anammox bacteria at different depths from $100 \mathrm{~nm}$ to $800 \mathrm{~nm}$

246 and the black arrows in Fig 4 indicate the nanoparticles with extremely high LAC values. The tomograph

247 of the anammox bacteria reconstructed with the TV-SART algorithm is shown in Supplementary Movie

248 4. The slice image and video show the LAC values of all areas inside the anammox bacteria. It is

249 noteworthy that some areas inside the anammoxosome membrane had low LAC values. In other words,

250 the structure inside the anammoxosome membrane was relatively dense but overall, the areas of high

251 soft X-ray absorption were discontinuous and inhomogeneous. 


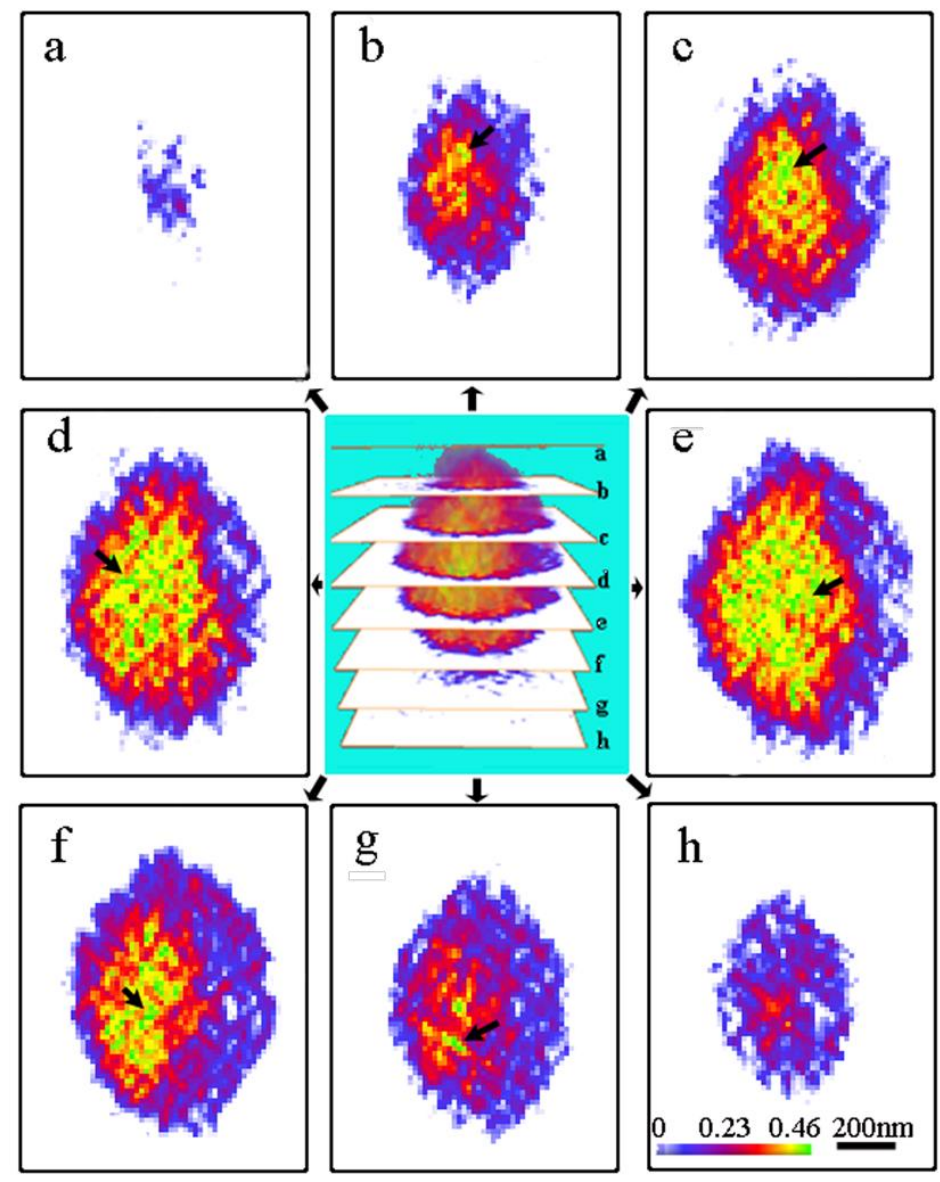

252 Fig 4. Slice images of the anammox bacteria cell at different depths. (a), (b), (c), (d), (e), (f), (g), and (h)

253 correspond to slice depths at $100 \mathrm{~nm}, 200 \mathrm{~nm}, 300 \mathrm{~nm}, 400 \mathrm{~nm}, 500 \mathrm{~nm}, 600 \mathrm{~nm}, 700 \mathrm{~nm}$, and $800 \mathrm{~nm}$

254 respectively

257 Since different biochemical components have specific LAC values, the organelles and other cell

258 structures can be distinguished visually based on the differences in the biochemical composition and

259 density $(39,42,43)$. Thus, the image of the ultrastructure of the anammox cell was segmented based on

260 the local LAC values using the Amira software, and the average LAC values of the anammox cell, the 
bioRxiv preprint doi: https://doi.org/101101/709188; this version posted July 22, 2019. The copyright holder for this preprint (which was not certified by peer review) is the author/funder. All rights reserved. No reuse allowed without permission.

261 anammoxosome, and the nanoparticles were calculated to be $0.326 \pm 0.001 \mu \mathrm{m}^{-1}, 0.389 \pm 0.001 \mu \mathrm{m}^{-1}$, and

$2620.460 \pm 0.001 \mu \mathrm{m}^{-1}$ respectively. The segmentation images of the anammox structure at different rotation

263 angles are shown in Fig 5. The video of the segmentation of the 3D structure is shown in Supplementary

264 Movie 5. The 3D segmentation structure of the anammox cell showed a distinct asymmetric structure,

265 especially at the rotation angles of $60^{\circ}$ and $240^{\circ}$ (Fig 5(a) and Fig 5(d)), which indicated the importance

266 of the 3D imaging of the intact anammox bacteria cells. Owing to the asymmetric distribution of the

anammoxosome, the nano-scale slices observed by TEM at certain angles or depths do not represent the

anammoxosome volume ratio.

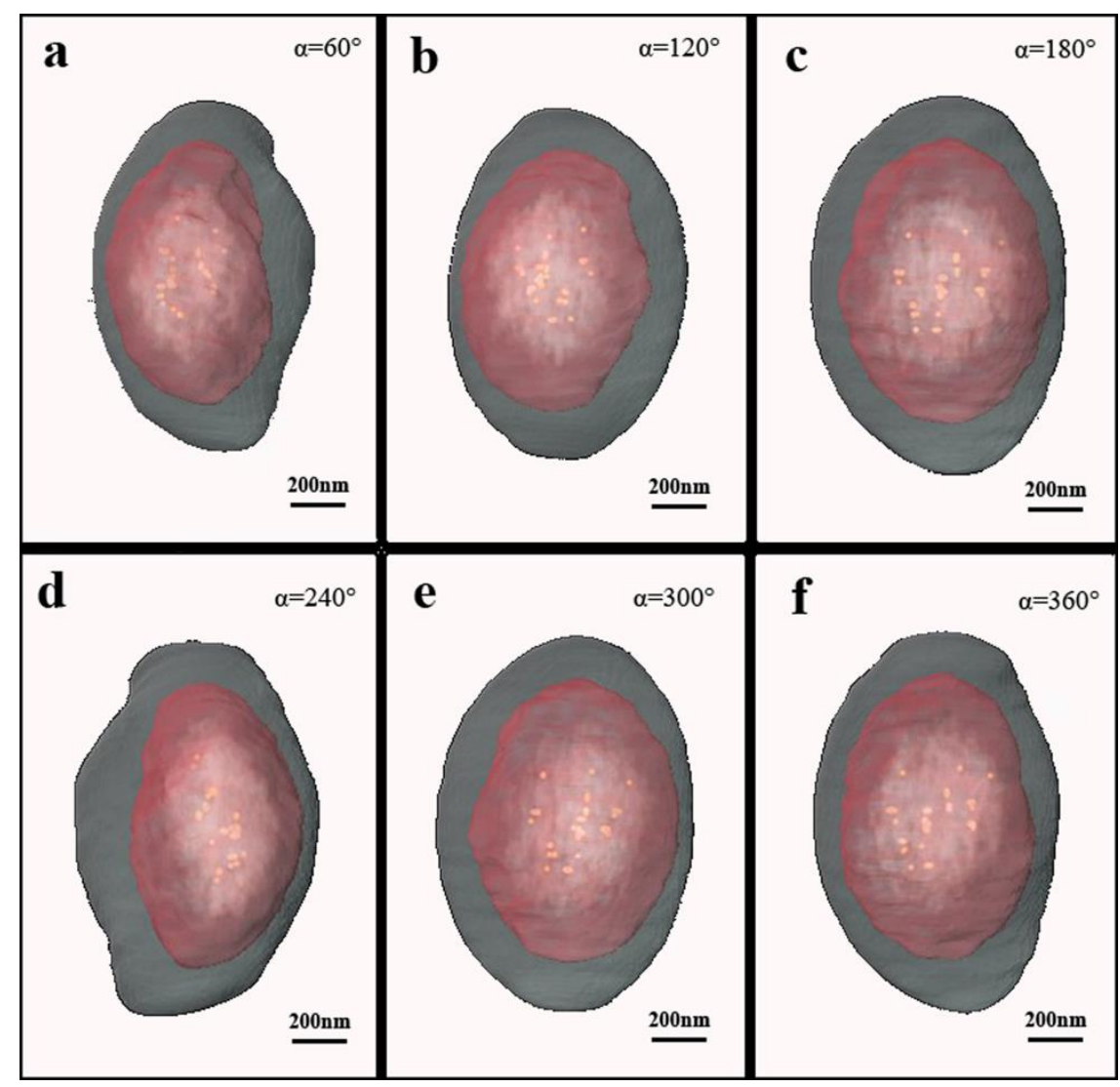

270 Fig 5. The segmentation images of the anammox cell at different rotation angles. (a), (b), (c), (d), (e),

271 and (f) correspond to $60^{\circ}, 120^{\circ}, 180^{\circ}, 240^{\circ}, 300^{\circ}$, and $360^{\circ}$, respectively. 
273 To quantify the anammoxosome volume ratio, anammox cells were reconstructed and statistically

274 analyzed using the Amira software. The ratio of the anammoxosome volume to the anammox bacteria

275 cell volume (A/C) was $47 \pm 2.5 \%$ (Fig S3). This value was much lower than the previously reported

276 volume ratio of $50 \%-80 \%$ with a large average error (11); the value was based on the area ratio of a

277 nanoscale slice in a TEM ultrathin section (11). However, the values of $\mathrm{A} / \mathrm{C}$ varied widely due to the

278 exocentric anammoxosome structure. To verify the structure of the anammox bacteria, TEM images of

279 the anammox bacteria slices were obtained in this study. Fig S4 (a), (b), and (c) represent different

280 distributions and sizes of the anammoxosome. The slice in Fig S4 (b) indicates that the anammoxosome

281 organelle account for the majority of the cell volume; however, the slice in Fig S4 (c) shows otherwise

282 although this was not the most extreme case. In fact, some nanoscale slices show no anammoxosome.

283 This may result in large differences in the A/C value. In this study, we calculated the volume ratio for

284 the total number of pixels, i.e., the ratio of the volume of the anammoxosome pixels to the number of

285 anammox cell pixels. The calculated volume ratio of the 3D reconstruction was almost equal to the actual

286 value. To quantify the exact position of the anammoxosome in the anammox cell, we used the parameter

287 of eccentricity $(e)$, which is defined as the ratio of the longest distance to the shortest distance from the

288 anammoxosome membrane to the cell membrane; this parameter reflects the degree of eccentricity of the

289 anammoxosome. The maximum and minimum eccentricity values of the anammoxosome are shown in

290 Fig S5. The average eccentricity is $3.25 \pm 0.43$ (Fig S3); this number demonstrates the extent to which

291 anammoxosome deviates from the center of the anammox bacteria. Although TEM imaging also provides

292 information on the eccentricity of anammox bacteria (de Almeida et al. 2015), this method requires 
complex preprocessing, such as fixing, dehydrating, embedding, and sectioning, resulting in changes in

294 the morphology of the anammox bacteria cell. Synchrotron soft X-ray imaging requires no pretreatment and the 3D nondestructive imaging of anammox bacteria cells can be performed in in-situ in the water.

Thus, the results of the anammoxosome volume ratio obtained by synchrotron soft X-ray imaging is closer to reality than that obtained by TEM. Further, the degree of eccentricity of the intact anammoxosome can be calculated from the synchrotron soft X-ray images but has not been determined from TEM images.

\section{Morphological analysis of the anammox bacteria response to $\mathrm{Fe}^{2+}$}

306 iron concentration from 0 to $0.06 \mathrm{mM}$. Accordingly, the $\mathrm{LAC}$ value changed with the $\mathrm{A} / \mathrm{C}$ volume ratio

307 (Fig 6(b)). In the absence of $\mathrm{FeSO}_{4}$ and in the presence of $0.015 \mathrm{mM} \mathrm{FeSO}_{4}$, the $\mathrm{LAC}$ value of the

308 anammoxosome was 0.220 and 0.301 respectively, representing $43 \%$ and $23 \%$ decreases in the LAC

309 value compared to the control group at $0.03 \mathrm{mM} \mathrm{FeSO}_{4}$. This may be related to two factors; one is the

310 increase in the anammoxosome volume, which, in turn, leads to a decrease in the density of the

311 anammoxosome. The other factor is that a low iron environment results in less iron accumulation in the

312 anammoxosome, thus reducing the soft $\mathrm{x}$-ray absorption ability. However, this is not applicable to the

313 response at a concentration of $0.06 \mathrm{mM}$, which is likely due to the flexibility of the anammoxosome and 
bioRxiv preprint doi: https://doi.org/101101/709188; this version posted July 22, 2019. The copyright holder for this preprint (which was not certified by peer review) is the author/funder. All rights reserved. No reuse allowed without permission.

314 the composition inside the anammoxosome outflow in response to the excessive iron concentration. This

315 result provides a new perspective of the inhibitory effect of excessive iron concentrations on anammox

316 bacteria. A similar response of anammox bacteria to iron has previously been observed using the TEM

317 method (44). An increase in the iron concentration from $0.03 \mathrm{mM}$ (Figure 6(c)) to $0.075 \mathrm{mM}$ (Figure

318 6(d)) resulted in a decrease in the electron absorption density and area of the anammoxosome (the dark

regions “D” in Figure $6(d)$ and (d)).
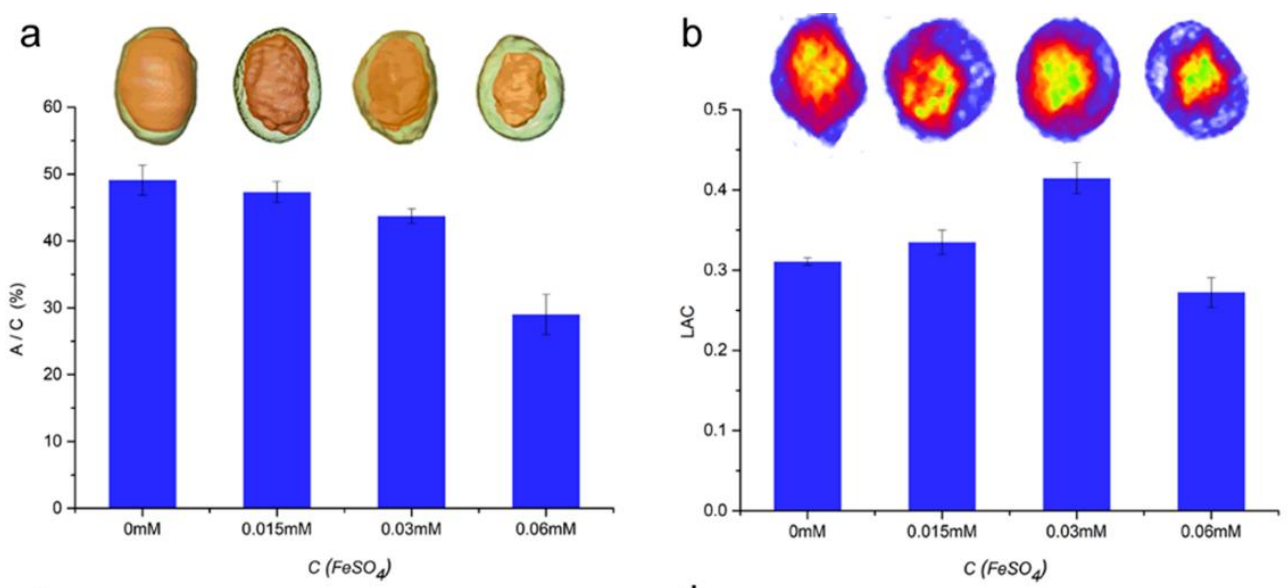

C

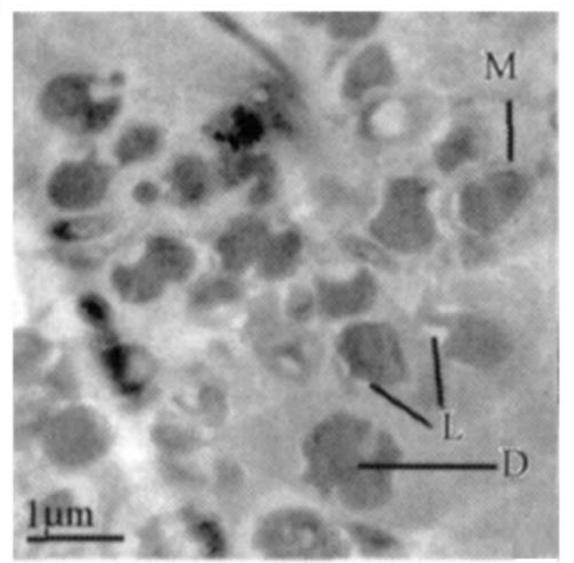

d

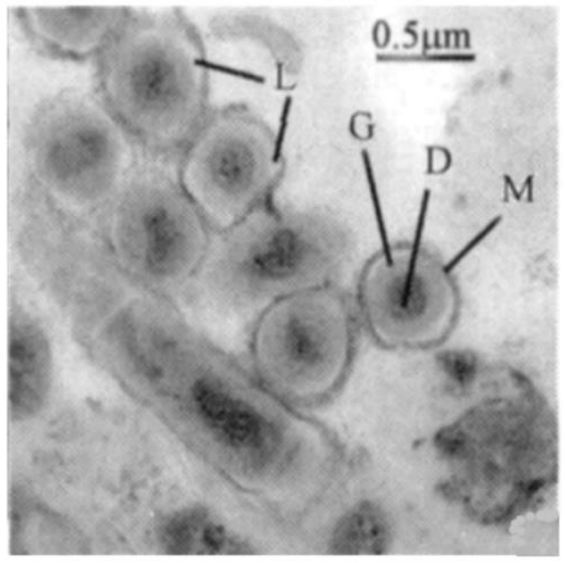

321 Fig 6. The effect of $\mathrm{Fe} 2+$ on the morphology of anammox bacteria. (a)The average A/C volume ratio at iron concentrations of $0,0.015 \mathrm{mM}, 0.03 \mathrm{mM}$, and $0.06 \mathrm{mM}$ respectively. (b) LAC values at iron concentrations of $0,0.015 \mathrm{mM}, 0.03 \mathrm{mM}$, and $0.06 \mathrm{mM}$ respectively. (c) and (d) are corresponding to the TEM imaging at the iron concentration of $0.03 \mathrm{mM}$ and $0.075 \mathrm{mM}(44)$. 


\section{Discussion}

reconstruction is used in the anammox bacteria morphology research for the first time. This novel method provided three-dimensional and interior ultrastructure information of the intact anammox bacteria in situ state.

331 LAC values of the chondriosome, vacuole, cell nucleus, and nucleoli were in the ranges of $0.34-0.38$, be calculated using the following equation (1) (39):

$$
\int_{L} \mu(x) d x=\ln \left(\frac{I_{\Delta}}{\mathrm{I}}\right)
$$

336 where $I_{0}$ is the initial X-ray intensity and $\mathrm{I}$ is the output X-ray intensity. $\mu(\mathrm{x})$ is the local LAC value,

337 which can be calculated by an iterative reconstruction using the TV-SART algorithm (40). The LAC

338 value was determined based on the mass absorption coefficient and the density of the composition, as

339 defined in the following equation (2):

$$
\mu=\mu_{\mathrm{m}} \times \rho
$$

341 where $\mu$ is the LAC, $\mu_{\mathrm{m}}$ is the mass absorption coefficient, and $\rho$ is the density of the composition.

342 Therefore, an area with a high LAC value is an area with a high mass absorption coefficient or high

343 density $(39,43)$. The extremely high LAC value of the anammoxosome organelle indicated that the 
344 biochemical composition and structure of the anammoxosome were denser than that of the conventional

345 organelles. Studies have shown that the anammox membrane contains abundant dense ladderane lipids

346 with $1.5 \mathrm{~g} / \mathrm{cm}^{3}$ density (14), resulting in higher LAC values of anammoxosome membrane than those of

347 the cytoplasm. The density of the anammoxosome membrane is related to its functions, because the dense

348 anammoxosome membrane plays an important role in preventing the leakage of valuable protons and

349 intermediates during the anammox process. Furthermore, the anammoxosome is the site of the ammonia

350 oxidation reaction that is associated with the presence of many enzymes. The high LAC values inside

351 the anammoxosome membrane may be related to the numerous enzymes inside the anammoxosome,

352 such as hydrazine dehydrogenase (HDH), hydrazine synthase (HZS), hydroxylamine/hydrazine

353 oxidoreductase (HAO/HZO) (12), or metal elements (10).

354 Morphological analysis of the anammox bacteria response to $\mathrm{Fe}^{2+}$ provides a new perspective on

355 underlying regulation mechanism of $\mathrm{Fe}^{2+}$ on anammox bacteria. The increased $\mathrm{A} / \mathrm{C}$ ratio was the most

356 characteristic shapes adaptation response of the anammox bacteria to $\mathrm{Fe}^{2+}$ hungry. An increase in the

$357 \mathrm{~A} / \mathrm{C}$ ratio resulted in a larger surface area of the anammoxosome. Further, the larger surface area

358 increased the number of metal binding sites (45). Thus, the shapeshifting of the anammox bacteria due

359 to the increased $\mathrm{A} / \mathrm{C}$ ratio at lower iron concentrations was presumed to enhance the iron absorption in

360 the face of iron starvation. Iron is a critical and abundant element in anammox bacteria. The dark red

361 color of the anammox bacteria is due to the abundance of iron and numerous iron-binding proteins ( 10 ,

$36246,47)$. Scalindua sp. and K. stuttgartiensis can use iron and manganese oxides as electron acceptors and

363 K. stuttgartiensis respires nitrate using iron as an electron donor $(48,49)$. In addition, these iron-binding

364 cytochromes play an important role in electron transfer (46) and the oxidation-reduction process (47) in 
365 the energy metabolism of anammox bacteria. Finally, another interesting form of iron, i.e., iron-

366 containing electron-dense nanoparticles was reported in the anammoxosome (10, 47). These

367 nanoparticles are relatively abundant in iron and phosphorus (10). Thus, it is probable that the anammox

368 bacteria adapt to an iron-limited environment by increasing the anammoxosome volume ratio to be able

369 to absorb more iron. This shapes adaptation mechanism is similar to that of the Mn-oxidizing bacteria

370 Halomonas meridiana and Marinobacter algicola, which adapt to Mn(II))-induced stress by increasing

371 the cell length and volume to achieve better Mn (II) oxidizing ability (21). This shapeshifting

372 phenomenon indicates a sensitivity and dependence of anammox bacteria to iron. In future studies, we

373 will investigate this mechanism of iron regulation in the anammox process in more detail.

\section{Conclusion}

377 breakthrough in intact anammox bacteria morphology research. This novel method provided high-

378 contrast and high-resolution 3D images of the whole anammox bacteria cell in its natural state. The

379 ultrastructure of the anammox bacteria was imaged and the linear absorption coefficient, anammoxosome

380 volume ratio, and eccentricity were quantified. On this basis, the shape adaptation and mechanism of the

381 anammox bacteria responses to $\mathrm{Fe}^{2+}$ were explored. Synchrotron soft X-ray nano-CT imaging technology

382 provides a new perspective for the study of the biophysical properties of cells in different environments 383 and engineering processes. 


\section{Author contributions}

All authors assisted with data interpretation and manuscript review. Y.-P.C, G.L, M-W.P, and Y. G conceived and designed the research. Y.-P.C and M-W.P analyzed the data. J.-H.L and L.C performed the TV-SART 3D reconstruction. H. W cultivated all the anaerobic granular sludge. H.-Y.L and P. L assisted with the synchrotron soft X-ray imaging experiments. Z.-Z. X conducted the TEM imaging experiments. P. Y purified the anammox bacteria and Y. S isolated the anammoxosome. Y.-P.C and G.L

391 performed the segmentation of the cell based on the LAC value. J.-S. G designed all figures with F.F and 392 with the help from all other authors. M.-W.P wrote the manuscript with help from all authors. and 51578527), the Chongqing Science and Technology Commission (cstc2018jcyjAX0366), the

398 Research \& Development Program of China (2016YFE0205600). We gratefully acknowledge Bing-

399 Hong Wan for the guidance on the Amira software, and the BL07W beamline at the National Synchrotron

400 Radiation Laboratory in Hefei, China; the supports of Majorbio, China.

\section{$401 \quad$ References}

402 1. Chen. L.M, Liu. S.T, Chen. Q, Zhu. G.B, Wu. X, Wang. J. W, Li. X. F, Hou. L.J, Ni. J.R.

403 2019. Anammox response to natural and anthropogenic impacts over the Yangtze River. Sci.

404 Total Environ. 665:171-180.

405 2. van de Vossenberg J, Woebken D, Maalcke WJ, Wessels HJCT, Dutilh BE, Kartal B, Janssen406 Megens EM, Roeselers G, Yan J, Speth D, Gloerich J, Geerts W, van der Biezen E, Pluk W, 
Francoijs K-J, Russ L, Lam P, Malfatti SA, Tringe SG, Haaijer SCM, Op Den Camp HJM, Stunnenberg HG, Amann R, Kuypers MMM, Jetten MSM. 2013. The metagenome of the marine anammox bacterium 'Candidatus Scalindua profunda' illustrates the versatility of this globally important nitrogen cycle bacterium. Environmental Microbiology 15(5):1275-1289.

3. Zhu. G.B, Wang. S.Y., Wang. Y, Wang. C.X, Risgaard-Petersen. N, Jetten. M. S. M, and Yin. C. Q. 2011. Anaerobic ammonia oxidation in a fertilized paddy soil. Isme J. 5(12):1905-1912.

4. Li, H., Chen. S, Mu. B.Z, and Gu. J.D. 2010. Molecular detection of anaerobic ammoniumoxidizing (Anammox) bacteria in high-temperature Petroleum Reservoirs. Microbial Ecology 60(4):771-783.

5. Ali M, Oshiki M, Awata T, Isobe K, Kimura Z, Yoshikawa H, Hira D, Kindaichi T, Satoh H, Fujii T. 2015. Physiological characterization of anaerobic ammonium oxidizing bacterium 'Candidatusâ Jettenia caeni'. Environmental Microbiology 17(6):2172-2189.

6. Strous, M., Pelletier, E., Mangenot, S., Rattei, T., Lehner, A., Taylor, M.W., Horn, M., Daims, H., Bartol-Mavel, D. and Wincker, P. 2006. Deciphering the evolution and metabolism of an anammox bacterium from a community genome. Nature. 440(7085):790-794.

7. Zhang. Z.Z, Cheng. Y.F, Liu. Y.Y, Zhang. Q, Zhu. B.Q, Jin RC. 2019. Deciphering the evolution characteristics of extracellular microbial products from autotrophic and mixotrophic anammox consortia in response to nitrogen loading variations. Environ. Int. 124:501-510.

8. Zhang ZZ, Cheng YF, Xu LZJ, Bai YH, Jin RC. 2018. Anammox granules show strong resistance to engineered silver nanoparticles during long-term exposure. Bioresource Technology. 259:10-17.

9. Innerebner G, Insam H, Frankewhittle IH, Wett B. 2007. Identification of anammox bacteria in a full-scale deammonification plant making use of anaerobic ammonia oxidation. Systematic \& Applied Microbiology. 30(5):408-412

10. van Niftrik L, Geerts WJC, van Donselaar EG, Humbel BM, Yakushevska A, Verkleij AJ, Jetten MSM, Strous M. 2008. Combined structural and chemical analysis of the anammoxosome: A membrane-bounded intracytoplasmic compartment in anammox bacteria. Journal of Structural Biology. 161(3):401-410.

11. van Niftrik, L., Geerts, W.J.C., van Donselaar, E.G., Humbel, B.M., Webb, R.I., Fuerst, J.A., Verkleij, A.J., Jetten, M.S.M. and Strous, M. 2008. Linking ultrastructure and function in four genera of anaerobic ammonium-oxidizing bacteria: Cell Plan, glycogen storage, and localization of cytochrome c proteins. Journal of Bacteriology. 190(2):708-717.

12. de Almeida, N.M., Neumann, S., Mesman, R.J., Ferousi, C., Keltjens, J.T., Jetten, M.S., Kartal, B. and van Niftrik, L. 2015. Immunogold localization of key metabolic enzymes in the anammoxosome and on the tubule-like structures of Kuenenia stuttgartiensis. J Bacteriol 197(14):2432-2441.

13. Neumann, S., H. J. C. T. Wessels, W. I. C. Rijpstra, J. S. Sinninghe Damsté, B. Kartal, M. S. M. Jetten, and L. van Niftrik. 2014. Isolation and characterization of a prokaryotic cell organelle from the anammox bacterium Kuenenia stuttgartiensis. Molecular Microbiology. 94(4):794-802. 
14. Damsté, J. S. S., M. Strous, W. I. C. Rijpstra, E. C. Hopmans, J. A. J. Geenevasen, A. C. T. V. Duin, L. A. V. Niftrik, and M. S. M. Jetten. 2002. Linearly concatenated cyclobutane lipids form a dense bacterial membrane. Nature. 419(6908):708-712.

15. Moss, F. R., 3rd, S. R. Shuken, J. A. M. Mercer, C. M. Cohen, T. M. Weiss, S. G. Boxer, and N. Z. Burns. 2018. Ladderane phospholipids form a densely packed membrane with normal hydrazine and anomalously low proton/hydroxide permeability. Proc Natl Acad Sci US A. 115(37):9098-9103.

16. Kysela, D. T., A. M. Randich, P. D. Caccamo, and Y. V. Brun. 2016. Diversity Takes Shape: Understanding the mechanistic and adaptive basis of bacterial morphology. PLoS. Biol. 14(10): 15 .

17. Woldemeskel, S. A., and E. D. Goley. 2017. Shapeshifting to Survive: Shape Determination and Regulation in Caulobacter crescentus. Trends Microbiol. 25(8):673-687.

18. Schmidt, J. M., and R. Y. Stanier. 1966. The development of cellular stalks in bacteria. J. Cell Biol. 28(3):423-436.

19. Poindexter, J. S. 1984. The role of calcium in stalk development and in phosphate acquisition in Caulobacter crescentus. Archives of microbiology. 138(2):140-152.

20. Caccavo, F., N. B. Ramsing, and J. W. Costerton. 1996. Morphological and metabolic responses to starvation by the dissimilatory metal-reducing bacterium Shewanella alga BrY. Appl. Environ. Microbiol. 62(12):4678-4682.

21. Fernandes, S. O., L. S. Prakash, M. B. Binish, K. P. Krishnan, and P. J. Kurian. 2018. Changes in morphology and metabolism enable Mn-oxidizing bacteria from mid-oceanic ridge environment to counter metal-induced stress. J. Basic Microbiol. 58(5):390-402.

22. Gambelli L, Cremers G, Mesman R, Guerrero S, Dutilh BE, Jetten MSM, Op den Camp HJM, van Niftrik L. 2016. Ultrastructure and viral metagenome of bacteriophages from an anaerobic methane oxidizing methylomirabilis bioreactor enrichment culture. Front. Microbiol. 7:15.

23. Wang, X., S.-H. Li, L. Zhu, Q.-G. Nian, S. Yuan, Q. Gao, Z. Hu, Q. Ye, X.-F. Li, D.-Y. Xie, N. Shaw, J. Wang, T. S. Walter, J. T. Huiskonen, E. E. Fry, C.-F. Qin, D. I. Stuart, and Z. Rao. 2017. Near-atomic structure of Japanese encephalitis virus reveals critical determinants of virulence and stability. Nature Communications. 8(1):9.

24. Milne, J. L. S., and S. Subramaniam. 2009. Cryo-electron tomography of bacteria: progress, challenges and future prospects. Nature Reviews Microbiology. 7(9):666-675.

25. Carolyn A Larabell, and K. A. Nugent. 2010. Imaging cellular architecture with X-rays. Current Opinion in Structural Biology. 20(5): 623-631.

26. Schneider, G., P. Guttmann, S. Heim, S. Rehbein, F. Mueller, K. Nagashima, J. B. Heymann, W. G. Müller, and J. G. McNally. 2010. Three-dimensional cellular ultrastructure resolved by X-ray microscopy. Nature Methods. 7(12):985-987.

27. Wang, L., Zhang, T., Li, P., Huang, W., Tang, J., Wang, P., Liu, J., Yuan, Q., Bai, R., Li, B., Zhang, K., Zhao, Y. and Chen, C. 2015. Use of synchrotron radiation-analytical techniques to reveal chemical origin of silver-nanoparticle cytotoxicity. ACS Nano. 9(6):6532-6547.

28. Pérez-Berná, A.J., Rodríguez, M.J., Chichón, F.J., Friesland, M.F., Sorrentino, A., Carrascosa, J.L., Pereiro, E. and Gastaminza, P. 2016. Structural changes in cells imaged by soft X-ray cryo-tomography during Hepatitis C Virus infection. ACS Nano. 10(7):6597-6611. 
29. Chiappi M, Conesa JJ, Pereiro E, Sorzano COS, Rodríguez MJ, Henzler K, Schneider G, Chichón FJ, Carrascosa JL. Carrascosa. 2016. Cryo-soft X-ray tomography as a quantitative three-dimensional tool to model nanoparticle:cell interaction. Journal of Nanobiotechnology. $14(1): 15$.

30. Xing, H., Wang, H., Fang, F., Li, K., Liu, L., Chen, Y. and Guo, J. 2017. Effect of increase in salinity on ANAMMOX-UASB reactor stability. Environ Technol. 38(9):1184-1190.

31. deGraaf, A.A.V., deBruijn, P., Robertson, L.A., Jetten, M.S.M., Kuenen, J.G. 1996. Autotrophic growth of anaerobic am monium-oxidizing micro-organisms in a fluidized bed reactor. Microbiology. 142(8): 2187-2196.

32. Strous, M., Fuerst, J. A., Kramer, E. H. M., Logemann, S., Muyzer, G., van de Pas-Schoonen, K. T., Webb, R., Kuenen, J. G., Jetten, M. S. M. 1999. Missing Lithotroph Identified as New Planctomycete. Nature. 400 446-449.

33. Zhang Z, Gong Z, Liu S, Ni J. 2016. Extracellular polymeric substances extraction induced the increased purification performance of percoll density gradient centrifugation for anammox bacteria. Chemical Engineering Journal. 287:529-536.

34. Schmid, M., Walsh, K., Webb, R., Rijpstra, W.I., van de Pas-Schoonen, K., Verbruggen, M.J., Hill, T., Moffett, B., Fuerst, J., Schouten, S., Sinninghe Damsté, J.S., Harris, J., Shaw, P., Jetten, M. and Strous, M. 2003. Candidatus “Scalindua brodae”, sp. nov., Candidatus "Scalindua wagneri”, sp. nov., Two new species of anaerobic ammonium oxidizing bacteria. Systematic and Applied Microbiology. 26(4):529-538.

35. Zheng, Z., Tang, A., Guan, Y., Chen, L., Wang, F., Chen, P., Wang, W., Luo, Y., Tian, Y. and Liang, G. 2016. Nanocomputed tomography imaging of bacterial alkaline phosphatase activity with an iodinated hydrogelator. Analytical Chemistry. 88(24):11982-11985.

36. Schneider, G., Niemann, B., Guttmann, P., Rudolph, D., Schmah. G. 1995. Cryo X - ray microscopy. Synchrotron Radiat News. 8: 19-28.

37. Carrascosa JL, Chichón FJ, Pereiro E, Rodríguez MJ, Fernández JJ, Esteban M, Heim S, Guttmann P, Schneider G. 2009. Cryo-X-ray tomography of vaccinia virus membranes and inner compartments. Journal of Structural Biology. 168(2):234-239

38. Liang, Z., Guan. Y., Liu, G., Bian, R., Zhang, X., Xiong, Y., Tian, Y. 2013. Reconstruction of limited-angle and few-view Nano-CT image via total variation iterative reconstruction. $X$-Ray Nanoimaging:Instruments and Methods. 8851, 13.

39. Weiss, D., Schneider, G., Niemann, B., Guttmann, P., Rudolph, D. and Schmahl, G. 2000. Computed tomography of cryogenic biological specimens based on X-ray microscopic images. Ultramicroscopy 84(3):185-197.

40. Liu J, Li F, Chen L, Guan Y, Tian L, Xiong Y, Liu G, Tian Y. 2017. Quantitative imaging of Candida utilis and its organelles by soft X-ray Nano-CT. Journal of Microscopy. 270:64-70.

41. Sinka IC, Burch SF, Tweed JH, Cunningham JC. 2004. Measurement of density variations in tablets using X-ray computed tomography. International Journal of Pharmaceutics. 271(12):215-224.

42. Uchida M, Sun Y, McDermott G, Knoechel C, Le Gros MA, Parkinson D, Drubin DG, Larabell CA. 2011. Quantitative analysis of yeast internal architecture using soft X-ray tomography. Yeast. 28(3):227-236. 
43. Le Gros MA, McDermott G, Larabell CA. 2005. X-ray tomography of whole cells. Current Opinion in Structural Biology. 15(5):593-600.

44. Zhang, L., Zheng, P., \& Hu, A. H. 2009. Effect of ferrous ion on the performance of an anammox reactor. Acta Scientiae Circumstantiae. 29(8):1629-1634.

45. Antony R, Sujith PP, Fernandes SO, Verma P, Khedekar VD, Bharathi PAL. 2011. Cobalt immobilization by manganese oxidizing bacteria from the Indian Ridge system. Current Microbiology. 62(3):840-849.

46. Kartal, B. and Keltjens, J.T. 2016. Anammox biochemistry: a tale of heme c proteins. Trends in Biochemical Sciences. 41(12):998-1001.

47. Ferousi C, Lindhoud S, Baymann F, Kartal B, Jetten MSM, Reiman J. 2017. Iron assimilation and utilization in anaerobic ammonium oxidizing bacteria. Current Opinion in Chemical Biology. 37:129-136.

48. Strous, M., Pelletier, E., Mangenot, S., Rattei, T., Lehner, A., Taylor, M.W., Horn, M., Daims, H., Bartol-Mavel, D. and Wincker, P. 2006. Deciphering the evolution and metabolism of an anammox bacterium from a community genome. Nature. 440:790-794.

49. Kartal B, Kuypers MMM, Lavik G, Schalk J, den Camp H, Jetten MSM, Strous M. 2007. Anammox bacteria disguised as denitrifiers: nitrate reduction to dinitrogen gas via nitrite and ammonium. Environmental Microbiology. 9(3):635-642.

551 Fig 1. Schematic of the synchrotron soft X-ray nano-CT imaging process of the anammox cell. (The

552 synchrotron soft X-ray was focused on the condenser, absorbed and scattered by the anammox bacteria,

553 then amplified by a condenser zone plate and detected by the charge coupled device (CCD).

554 Fig 2. The anaerobic granular sludge in the EGSB reactor. (a) Anaerobic granular sludge sampled from

555 the EGSB reactor. Scale bar shows $20 \mathrm{~mm}$. (b) Microbial diversity analysis of the anaerobic granular

556 sludge. (c) Confocal laser scanning microscope image of the anaerobic granular sludge. (Scale bar shows

$557200 \mu \mathrm{m}$.) (The probe Amx368 targeting the anammox bacteria is shown in red and the DAPI dye targeting

558 the total biomass minus the anammox bacteria is shown in blue.) 
559 Fig 3. The intact anammox cell reconstructed using the TV-SART algorithm. (a), (b), (c), (d), (e), and (f)

560 correspond to $60^{\circ}, 120^{\circ}, 180^{\circ}, 240^{\circ}, 300^{\circ}$, and $360^{\circ}$, respectively. (3D reconstruction of anammox

561 bacteria at different rotation angles with $60^{\circ}$ intervals.)

562 Fig 4. Slice images of the anammox bacteria cell at different depths. (a), (b), (c), (d), (e), (f), (g), and (h)

563 correspond to slice depths at $100 \mathrm{~nm}, 200 \mathrm{~nm}, 300 \mathrm{~nm}, 400 \mathrm{~nm}, 500 \mathrm{~nm}, 600 \mathrm{~nm}, 700 \mathrm{~nm}$, and $800 \mathrm{~nm}$

564 respectively (The black arrow points to nanoparticles in green. The scale bar and colormap in Figure $\mathrm{h}$

565 apply to all images).

566 Fig 5.The segmentation images of the anammox cell at different rotation angles. (a), (b), (c), (d), (e), and

567 (f) correspond to $60^{\circ}, 120^{\circ}, 180^{\circ}, 240^{\circ}, 300^{\circ}$, and $360^{\circ}$, respectively. ( $\alpha$ represents the rotation angle).

568 Fig 6. The effect of $\mathrm{Fe}^{2+}$ on the morphology of anammox bacteria. (a)The average $\mathrm{A} / \mathrm{C}$ volume ratio at

569 iron concentrations of $0,0.015 \mathrm{mM}, 0.03 \mathrm{mM}$, and $0.06 \mathrm{mM}$ respectively. (b) LAC values at iron

570 concentrations of $0,0.015 \mathrm{mM}, 0.03 \mathrm{mM}$, and $0.06 \mathrm{mM}$ respectively. (c) and (d) are corresponding to

571 the TEM imaging at the iron concentration of $0.03 \mathrm{mM}$ and $0.075 \mathrm{mM}$ (44). (Morphological analysis of

572 anammox bacteria response to $\mathrm{Fe}^{2+}$ ) 